\title{
Prevalence of 'Candidatus Liberibacter solanacearum' Haplotypes in Potato Tubers and Psyllid Vectors in Idaho From 2012 to 2018
}

\author{
Jennifer Dahan, ${ }^{1}$ Erik J. Wenninger, ${ }^{2}$ Brandon D. Thompson, ${ }^{1}$ Sahar Eid, ${ }^{1}$ Nora Olsen, ${ }^{3}$ and Alexander V. Karasev ${ }^{1, \dagger}$ \\ ${ }^{1}$ Department of Entomology, Plant Pathology and Nematology, University of Idaho, Moscow, ID \\ ${ }^{2}$ Department of Entomology, Plant Pathology and Nematology, Kimberly Research and Extension Center, University of Idaho, \\ Kimberly, ID \\ ${ }^{3}$ Department of Plant Sciences, Kimberly Research and Extension Center, University of Idaho, Kimberly, ID
}

\begin{abstract}
'Candidatus Liberibacter solanacearum' (Lso) is an uncultured, phloemassociated bacterium causing a severe tuber disease in potato called zebra chip (ZC). Seven haplotypes of Lso have been described in different hosts, with haplotypes A and B found associated with infections in potato and tomato. In the field, Lso is transmitted by the potato psyllid (Bactericera cockerelli), and between 2011 and 2015, a significant change in Lso haplotype prevalence was previously reported in Idaho: from exclusively A haplotype found in tested psyllids in 2012 to mainly B haplotype found in collected psyllids in 2015. However, prevalence of Lso haplotypes in Idaho was not analyzed in potato tubers exhibit-

exclusively A haplotype in the 2012 season to an almost equal A and B haplotype distribution during the 2016 season. During the same period, haplotype distribution of Lso in psyllid vectors collected using yellow sticky traps also changed, but in psyllids, the shift from A haplotype of Lso to B haplotype was complete, with no A haplotype detected in 2016 to 2018 . The changes in the haplotype prevalence of the Lso circulating in potato fields in southern Idaho may be, among other factors, responsible for a decrease in the $\mathrm{ZC}$ incidence in Idaho potato fields between an outbreak of the disease in 2012 and a very low level of ZC afterward.
\end{abstract} ing symptoms of ZC. To fill in this knowledge gap, prevalence of Lso haplotypes was investigated in potato tubers harvested in southern Idaho between 2012 and 2018, and it was found to change from
Keywords: disease development and spread, epidemiology, prokaryotes, vegetables
Zebra chip (ZC) disease is a bacterial infection of potato plants that triggers a variety of symptoms ranging from scorching and leaf rolling to stunting and ultimately, death (Munyaneza 2012, 2015). In addition to severe tuber yield losses in infested fields, ZC affects tuber quality, because infected tubers develop discolored necrotic lesions around or within the vascular system in the flesh. These lesions are dramatically aggravated by the frying processes, turning into dark streaks, altering flavor quality, and rendering the affected tubers unmarketable for the fried potato-derived product industry (Liefting et al. 2009; Munyaneza et al. 2007; Wen et al. 2009).

First detected in Mexico in 1994, ZC disease spread over Central America and northward into the United States, where it was first recorded in Texas fields in 2000 (Secor and Rivera-Varas 2004); it was later detected in the Pacific Northwest area in 2011. It resulted in an outbreak in potato fields of the Columbia Basin in Oregon and Washington, and the same year, tubers infected with 'Candidatus Liberibacter solanacearum' (Lso) were also reported in Idaho (Crosslin et al. 2012a, b; Rondon 2012). ZC has also been found in New Zealand, where it had major economic impacts on potato production (Liefting et al. 2008, 2009; Pitman et al. 2011). Consequently, during the past 10 years, $\mathrm{ZC}$ has been established as a

\footnotetext{
${ }^{\dagger}$ Corresponding author: A. V. Karasev; akarasev@uidaho.edu
}

Funding: This work was funded in part through the U.S. Department of Agriculture (USDA)-TASC, the Idaho State Department of Agriculture, USDA-ARS grants 58-5354-2-345 and 58-5352-4-006, the Northwest Potato Research Consortium, the Idaho Potato Commission, USDA-NIFA Hatch Project IDA01560, the Idaho Agricultural Experiment Station, and the National Potato Promotion Board.

The author(s) declare no conflict of interest.

Accepted for publication 30 April 2019.

(C) 2019 The American Phytopathological Society major threat to the potato tuber industry in the United States, impacting production and triggering efforts to control the disease.

ZC disease has been associated with Lso, an uncultured, phloemrestricted Alphaproteobacteria (Hansen et al. 2008; Liefting et al. 2009; Secor et al. 2009). Lso has been found to naturally infect a range of cultivated solanaceous species, like Solanum lycopersicon (tomato), Capsicum annuum (pepper), and Solanum melongena (eggplant), as well as perennial solanaceaous weeds, including Solanum dulcamara (bittersweet nightshade) and Lycium barbarum (wolfberry) (Munyaneza et al. 2009a, 2013, 2014; Thinakaran et al. 2017; Wen et al. 2009). The bacterium Lso is present on different crops in Europe and North Africa, where it is responsible for a range of vegetative disorders in apiaceous species, mainly Daucus carota (carrots) and Apium graveolens (celery) (Alfaro-Fernández et al. 2017; Hajri et al. 2017; Holeva et al. 2017; Nelson et al. 2013; Tahzima et al. 2017; Teresani et al. 2014). So far, seven haplotypes of Lso have been described, designated A, B, C, D, E, F, and U (Haapalainen et al. 2018; Liefting et al. 2008; Nelson et al. 2011, 2013; Teresani et al. 2014; Wen et al. 2009). Haplotypes A (LsoA) and B (LsoB) are associated with ZC and similar diseases in solanaceous plants, including potato, in the Americas and New Zealand, whereas haplotypes C, D, E, and U are found in Europe and the Mediterranean regions, infecting apiaceous species (LsoC, LsoD, and LsoE) or Urticaceae (LsoU)-related species. Haplotype F was described in a single potato tuber grown in the Pacific Northwest, but no other data are available on its prevalence and distribution (Swisher Grimm and Garczynski 2018). It was shown that LsoB caused more severe symptoms in Washington- and Texas-grown potato plants (Harrison et al. 2019; Swisher Grimm et al. 2018). LsoA and LsoB exhibit different geographical distributions, with both haplotypes present in North America and Central America, whereas only LsoA has been found in New Zealand so far.

The wide geographical and interspecies dispersal of Lso in Solanaceae hosts is facilitated through transmission from infected plants to healthy ones by its vector, the potato/tomato psyllid Bactericera cockerelli Šulc (Hemiptera: Triozidae). Endemic to Central America and the western United States, the psyllid can complete its lifecycle 
on a wide range of solanaceous plants and carries Lso at all life stages (Munyaneza 2012). Psyllid population is thus an important factor in ZC disease outbreaks, and most of the efforts to control ZC have been focused on managing the insect in potato fields during the growing season, incurring large costs of insecticide applications for growers. To aid in managing $\mathrm{ZC}$ in potato fields, monitoring programs have been set up in potato-growing areas over the United States, including southern Idaho (Wenninger et al. 2017), which represents around $31 \%$ of the potato production in the United States (U.S. Department of Agriculture-Economic Research Service 2016). The program in southern Idaho, set up since the 2012 season, has been very useful to track psyllid population and their Lso infection status in potato fields. Monitoring has also allowed for tracking of psyllid population composition, because four haplotypes of the psyllids have been described and named based on their geographical associations in the United States: Western, Northwestern, Central, and Southwestern (Swisher et al. 2012, 2013a, 2014). Although all four can be found in Idaho, the Western haplotype is predominant in potato fields. No significant differences in Lso transmission have been found among haplotypes so far (Mustafa et al. 2015). Since the start of the monitoring in 2012, Lso was found persisting in psyllids found in the fields at a low rate ( $<3 \%$ of the monitored psyllids), with the exception of the 2012 season, where it reached 26\% (Dahan et al. 2017; Wenninger et al. 2017).

To complement the data already available for Lso presence in Idaho potato fields, the purpose of this study was to assess the presence of the bacterium in tubers grown in southern Idaho that were exhibiting symptoms of ZC disease along with haplotyping positive samples to characterize the population of Lso present in plants. We also report here the results of Lso testing on psyllids from the 2016 to 2018 seasons, with tuber testing covering the period from 2012 to 2018 .

\section{Materials and Methods}

Psyllid monitoring. Monitoring of psyllids in the fields was performed as described in Wenninger et al. (2017). Briefly, yellow sticky cards were deployed in selected potato fields located in the main potato-growing areas of southern Idaho and replaced every week from planting to vine killing during 2016, 2017, and 2018. Caught psyllids were recovered individually from each sticky card and stored at $-20^{\circ} \mathrm{C}$ in $70 \%$ (vol/vol) ethanol for additional analysis.

Tuber sampling. Overall, 272 tubers were collected or submitted from industry personnel and tested based on visual symptoms spotted after harvest and during storage. The symptoms included typical signs of ZC, such as brown discolorations of the fresh tuber flesh within the vascular system, and less clear signs, such as various discolorations of the tuber flesh. All tubers from 2012 to 2018 were grown in potato fields and/or stored in southern Idaho and selected for suspected ZC symptoms. In 2016 and 2017, some of the tested tubers (74 and 1, respectively) were submitted directly for Lso testing from a potato processing and storage facility in southern Idaho (provided by Justin Ruhl, J.R. Simplot, Nampa, ID).

DNA extraction. For psyllids, the procedure followed was the one described in the work by Dahan et al. (2017) with no modification. For tubers collected in 2012, DNA extraction performed on skin pieces followed the protocol of Dellaporta et al. (1983). For tubers grown during the 2013 to 2018 seasons, stolon insertion site was collected on the tubers to be tested whenever possible along with one "eye" and/or skin pieces when possible, and they were extracted using a hexadecyltrimethylammoniumbromide (CTAB) extraction method as follows. Samples were frozen in liquid nitrogen and then ground using precooled mortars and pestles. Powder was recovered and transferred to a $1.5-\mathrm{ml}$ microtube, and $600 \mu \mathrm{l}$ of CTAB extraction buffer (2\% CTAB, $1.4 \mathrm{M} \mathrm{NaCl}, 0.2 \%$ 2-mercaptoethanol, $20 \mathrm{mM}$ EDTA, and $100 \mathrm{mM}$ Tris- $\mathrm{HCl}, \mathrm{pH} 8.0$ ) was added to resuspend ground tissue. Suspensions were thoroughly vortexed and incubated for $15 \mathrm{~min}$ at $65^{\circ} \mathrm{C}$ with shaking. Three hundred microliters of a 24:1 (vol/vol) chloroform:isoamyl alcohol mixture was dispensed to each tube, and the samples were vortexed for a few seconds to ensure complete mixing of aqueous and organic phases. They were then centrifuged for $10 \mathrm{~min}$ at $16,000 \times g$ at $4{ }^{\circ} \mathrm{C}$, and the aqueous phase was transferred to a new tube containing $50 \mu \mathrm{l}$ of $3 \mathrm{M}$ sodium acetate, $\mathrm{pH}$ 5.6. After gentle mixing by inversion, tubes were incubated $1 \mathrm{~h}$ to overnight at $-20^{\circ} \mathrm{C}$. DNA was pelleted by centrifugation at $25,000 \times g$ for $15 \mathrm{~min}$ at $4^{\circ} \mathrm{C}$. Pellets were washed with $1 \mathrm{ml} 70 \%$ ethanol, centrifuged at $12,000 \times g$ for $5 \mathrm{~min}$ at $4^{\circ} \mathrm{C}$, and air dried after decanting the supernatant. DNA pellets were resuspended in $50 \mu$ l of dideionized $\mathrm{H}_{2} \mathrm{O}$ facilitated by heating at $55^{\circ} \mathrm{C}$ for $10 \mathrm{~min}$.

Lso testing and haplotyping. Lso testing was carried out using the primer pairs OA2/OI2c and OMB_F/OMB_R (Crosslin et al. 2011) and the CAPS_F/CAPS_R primer pairs (Dahan et al. 2017). For psyllid testing, PCR were performed as described in Dahan et al. (2017). For tuber testing, resuspended DNA was diluted 1:10 in water before use, and $1 \mu l$ of the diluted material was used in PCR. The nested PCR using the pair CAPS_F/CAPS_R2 was performed on the PCR product from the CAPS_F/CAPS_R amplification diluted at 1:100, which was carried out as described in Dahan et al. (2017). As a control of amplification for tuber samples, the internal transcribed spacer region of nuclear ribosomal DNA of Solanum tuberosum was amplified (primers ITSLeu1, 5'-GTC CAC TGA ACC TTA TCA TTT AG-3' and ITS4, 5'-TCC TCC GCT TAT TGA TAT GC-3') (Bohs and Olmstead 2001) for the 2016 and subsequent years samples. Lso haplotyping was carried out on positive samples (tuber or psyllid) based on the results of the CAPS_F/CAPS_R or CAPS_F/CAPS_R2 nested PCR and using the cleaved amplified polymorphic sequence (CAPS) technique as described in Dahan et al. (2017). Briefly, 5 or $10 \mu$ l of PCR products were digested by the Bsl1 restriction enzyme, and results were analyzed on an ethidium bromide-stained $2 \%$ agarose gel. Lsopositive psyllids and some of the tuber samples proved to be difficult to reamplify after the first round of testing, precluding their haplotyping.

\section{Results}

Psyllid population in south Idaho potato fields for the 2016, 2017, and 2018 seasons. The three covered seasons were contrasting in terms of numbers of psyllids collected (Table 1). During the 2016 season, 6,519 psyllids were collected on sticky cards and tested for Lso, 91 of which were found to be positive for the bacterium (Table 1). In the two subsequent years, the number of collected psyllids dropped to 883 in 2017 and 490 in 2018, with 5 and 3 Lsopositive psyllids caught, respectively. The Lso incidence was low

Table 1. Numbers of total and 'Liberibacter solanacearum' (Lso)-positive psyllids collected on sticky cards in Idaho potato fields during each month of the 2016 to 2018 growing seasons

\begin{tabular}{|c|c|c|c|c|c|c|c|c|c|c|c|c|c|c|c|c|}
\hline \multirow[b]{3}{*}{ Year } & \multicolumn{12}{|c|}{ Collecting month ${ }^{\mathrm{z}}$} & & & & \\
\hline & \multicolumn{2}{|c|}{ May } & \multicolumn{2}{|c|}{ June } & \multicolumn{2}{|c|}{ July } & \multicolumn{2}{|c|}{ August } & \multicolumn{2}{|c|}{ September } & \multicolumn{2}{|c|}{ October } & \multicolumn{2}{|c|}{ Total } & \multicolumn{2}{|c|}{ Lso haplotypes } \\
\hline & $\bar{a}$ & $\bar{b}$ & $a$ & $\bar{b}$ & $a$ & $\bar{b}$ & $a$ & $\bar{b}$ & $a$ & $b$ & $a$ & $b$ & $a$ & $b$ & $c$ & $d$ \\
\hline 2016 & 3 & 2 & 177 & - & 794 & 85 & 3,652 & 4 & 1,836 & - & 54 & - & 6,519 & 91 & 36 & $\mathrm{~B}$ \\
\hline 2017 & 8 & - & 24 & 1 & 188 & 4 & 163 & - & 445 & - & 54 & - & 882 & 5 & 4 & $\mathrm{~B}$ \\
\hline 2018 & 1 & - & 43 & 1 & 133 & 1 & 146 & - & 164 & 1 & 3 & - & 490 & 3 & 3 & $\mathrm{~B}$ \\
\hline
\end{tabular}

${ }^{\mathrm{z}}$ No collection date could be assigned to three Lso-negative psyllids. $a$, number of collected psyllids; $b$, number of Lso-positive psyllids; $c$, number of Lso-positive samples haplotyped; $d$, Lso haplotype found. Dashes indicate no psyllids. 
overall, with $1.4,0.6$, and $0.6 \%$ of the psyllids testing positive in 2016, 2017, and 2018, respectively. Interestingly, in 2016, most of the positive psyllids were found in July. Of the 794 psyllids collected and tested during that month in 2016, 85 were positive, which represents $10.7 \%$. It is noteworthy that, although 3,652 psyllids were retrieved in August 2016, only 4 psyllids were found carrying the pathogen $(0.1 \%)$. Likewise, in 2017 , four psyllids of the five carrying Lso were also caught in July. In 2018, the three Lso-positive psyllids were distributed between June, July, and September catches (Table 1). In terms of the Lso haplotype, over the three considered seasons, all of the individual psyllids testing positive for the bacterium that could be haplotyped were found to carry LsoB (Table 1).

Geographically, in 2016 and 2018, most of the psyllids were collected in the Treasure Valley of southwestern Idaho: 5,712 of 6,519 and 373 of 490, respectively. In each case, Lso-positive psyllids were mostly collected in the Treasure Valley as well (Table 2) (Wenninger et al. 2017). In 2017, an opposite trend was observed, with $64 \%$ of the psyllids collected in the Magic Valley of southcentral Idaho as well as three of the five Lso-positive psyllids (Table 2) (Wenninger et al. 2017).

Tuber testing between 2012 and 2018. At the end of the 2012 potato-growing season and during storage, 176 tubers from potato plants grown in Idaho were tested for the presence of Lso (Table 3). In total, 48 tubers were found positive: 41 during the first round of screening in 2012 using primer pairs OA2/OI2C and OMBF/OMBR and 7 more detected as Lso positive during the retroactive screening using the nested PCR with the CAPS primers developed for haplotyping and conducted in 2017. Only 16 samples detected as Lso positive during the first screening were also found positive in the second one, meaning that 25 of the samples found in the first round of Lso testing could not be haplotyped. The 23 Lso-positive samples that were haplotyped were all found to be LsoA.

Over the 2013 to 2015 seasons, eight symptomatic tubers collected in southern Idaho were tested for Lso (Table 3). Very few tubers exhibiting visible ZC symptoms were identified and tested during this period, but a few tubers each year were found positive for Lso. Haplotyping of Lso in positive tuber samples from 2013 and 2014 seasons revealed the presence of LsoB only, whereas LsoA was found again in two tubers of the three that tested positive in 2015.

In 2016, 79 tubers from potato plants grown in Idaho were tested for Lso infection based on presence of ZC-like symptoms (Table 3). Among them, 44 were found to be positive for the pathogen. Both haplotypes of the bacteria, LsoA and LsoB, could be detected: 22 samples carried LsoA, whereas 18 samples were infected with LsoB. Two samples had a mixed infection, with both haplotypes LsoA and LsoB present in the same tuber. In 2017, three symptomatic tubers were tested, and the two that turned out positive for the bacterium were found to carry LsoB, consistent with LsoB found in psyllids this same season. In 2018, five Lso-positive tubers of the six tested were carrying LsoA, which was different from LsoB found in psyllids.

\section{Discussion}

After the ZC outbreak in the states of Washington and Oregon and its first report in Idaho in 2011 (Crosslin et al. 2012a, b; Rondon 2012), efforts were made to manage and study the psyllid populations colonizing the potato fields of the Pacific Northwest, Idaho included (Munyaneza et al. 2009b; Rondon 2012; Wenninger et al. 2014). Data were collected about psyllids and their Lso status as well as respective haplotypes of the pathogen and its vector from 2012 to 2015 in Idaho (Dahan et al. 2017; Wenninger et al. 2017), and this monitoring was also performed for the 2016 to 2018 seasons as reported here. In addition to this testing, we gathered data on Lso presence in symptomatic potato tubers collected after harvest in Idaho from 2012 to 2018.

During the 2016 potato-growing season, a high number of psyllids were collected on sticky cards in Idaho fields, mainly in August and September, totaling $>6,500$ insects (Table 1). This number was exceptionally high compared with the numbers of psyllids collected from 2013 to 2015 and also between 2017 and 2018 using a similar collection setup, which ranged from 170 to 1,603 individuals collected (Wenninger et al. 2017) (this study). In 2012, however, the population of psyllids captured was notably higher than in the subsequent years, taking into account the much restricted setup used with a smaller number of fields covered (Wenninger et al. 2017). Given this discrepancy, it is expected that the extent of infestation in 2012 was not fully assessed and that it was probably closer to the 2016 season in terms of psyllid numbers. Interestingly, 2012 also featured the highest percentage of Lso-carrying psyllids detected in the Idaho monitoring program $(26 \%)$. The percentage of positive psyllids in 2016 was much lower and similar to the levels recorded from 2013 to 2015 and from 2017 to 2018 , reaching only $1.4 \%$ (Dahan et al. 2017) (this study). However, looking at per-month distribution in 2016, around $10 \%$ of the psyllids collected in July carried the pathogen (Table 1). This number may be viewed as high enough to qualify as an outbreak of the psyllid population and concomitantly, ZC disease, similar to 2012 (Wenninger et al. 2014). As can be seen here, this assertion is supported by the higher than usual number of symptomatic tubers tested and found positive that same year (Table 3). The timing of the peak in Lso-positive psyllids in July could be linked to that higher number of symptomatic tubers at the end of the season. Indeed, it has been shown that timing of infection during the growing season determines severity of tuber symptoms at harvest, with 80 to $95 \%$ of tubers showing symptoms when the plant was infected $\geq 4$ weeks before harvest (Rashed et al. 2014). It is also interesting to note that most of the Lso-positive psyllids in 2017 and 2018 were collected at the end of June and in July as well (Table 1).

Origins of Lso-carrying psyllids found in potato fields in Idaho are still undetermined. Although the first appearance of Lso in the Pacific Northwest could be owing to introduction of psyllids coming from infected plants from southern states, the continued presence of Lso in potato in Idaho at a very low rate since then is puzzling, because no local source of the bacterium could be identified to the best of our knowledge, although infected psyllids might overwinter on alternative hosts in the Pacific Northwest, including the potato-growing regions of Idaho (Swisher et al. 2013b; Thinakaran et al. 2017;

Table 2. Geographical origin of psyllids collected from 2016 to 2018

\begin{tabular}{lccc}
\hline Area & $\mathbf{2 0 1 6}^{\mathbf{w}}$ & $\mathbf{2 0 1 7}$ & $\mathbf{2 0 1 8}$ \\
\hline Magic Valleyx & $781(13)$ & $565(3)$ & 114 \\
Treasure Valley $^{\mathrm{y}}$ & $5,712(78)$ & $266(1)$ & $373(3)$ \\
Others $^{\mathrm{z}}$ & 26 & $52(1)$ & 3 \\
\hline
\end{tabular}

${ }^{\mathrm{w}}$ Numbers of collected psyllids are given for each year and geographical area considered, and numbers of 'Liberibacter solanacearum'-positive psyllids are indicated in parentheses.

${ }^{x}$ Magic Valley covers the following counties in southcentral Idaho: Blaine, Cassia, Gooding, Jerome, Minidoka, and Twin Falls.

y Treasure Valley covers the following counties in southwest Idaho: Ada, Canyon, Elmore, Gem, Owyhee, and Payette.

z Others includes the counties of Bannock, Bingham, Oneida, and Power in southeast Idaho.

Table 3. Numbers of total and 'Liberibacter solanacearum' (Lso)-positive tubers tested grown from the 2012 through the 2018 seasons and Lso haplotyping data

\begin{tabular}{|c|c|c|c|c|c|}
\hline \multirow[b]{2}{*}{ Year } & \multirow{2}{*}{$\begin{array}{l}\text { No. of tested } \\
\text { symptomatic } \\
\text { tubers }\end{array}$} & \multirow{2}{*}{$\begin{array}{c}\text { No. of Lso-positive } \\
\text { tubers } \\
\text { (haplotyped) }\end{array}$} & \multicolumn{3}{|c|}{ Haplotyping } \\
\hline & & & $\overline{\mathbf{A}}$ & B & Mixed $^{\mathbf{z}}$ \\
\hline 2012 & 176 & $48(23)$ & 23 & - & - \\
\hline 2013 & 1 & $1(1)$ & - & 1 & - \\
\hline 2014 & 3 & $1(1)$ & - & 1 & - \\
\hline 2015 & 4 & $3(3)$ & 2 & 1 & - \\
\hline 2016 & 79 & 44 (44) & 22 & 18 & 4 \\
\hline 2017 & 3 & $2(2)$ & - & 2 & - \\
\hline 2018 & 6 & $5(5)$ & 5 & - & - \\
\hline
\end{tabular}

${ }^{\mathrm{z}}$ This includes tubers infected with both haplotypes (two samples in 2016) and different Lso-positive tubers from the same sample harboring different haplotypes (two samples in 2016). Dashes indicate no sample. 
Wenninger et al. 2019), providing a limited local source. However, such a mechanism has not been demonstrated for Lso so far, and furthermore, haplotyping of Lso present in the 2016 Lso-positive insects gave unexpected results, with all samples that could be haplotyped being LsoB, as well as for the two subsequent seasons (Table 1). This contrasted with the results from the previous years where, except for in 2012 (all haplotyped samples were LsoA), both haplotypes could be found (Dahan et al. 2017). Interestingly, the proportion of LsoB in haplotyped psyllid samples kept increasing since the first appearance of LsoB in Idaho field during the 2013 season. No data are available that could help understand that result, because origins of positive Lso psyllids in the area are still undetermined.

Based on the testing of symptomatic tubers, we reported here the presence of the bacterium Lso, responsible for the ZC disease, in southern Idaho potato fields during the 2012 and 2018 seasons. Although no outbreak of the ZC disease was reported in Idaho for the 2011 potato season as opposed to Washington and Oregon states, the pathogenic bacterium could be detected in a total of 83 potato tubers exhibiting typical symptoms of $\mathrm{ZC}$ found in an Idaho packing facility and during storage (Crosslin et al. 2012a; Wen et al. 2013). In 2012, Lso infestation was very obvious in potato-growing areas along the Snake River and was confirmed by the psyllid monitoring set up that year (Dahan et al. 2017). Symptomatic plants were observed in potato fields, and although most of the fields were clear of ZC disease, in some areas the infection level reached up to 15 to $20 \%$ (Wenninger et al. 2014, 2017). Accordingly, 27\% of the 176 tested symptomatic tubers were positive for Lso (Table 3). Numbers of positive psyllids were also exceptionally high overall, with $>26 \%$ of the tested psyllids found carrying the bacterium (Dahan et al. 2017). Given the extremely high numbers of psyllids caught in 2016, this season can also be tentatively labeled an outbreak year for both the number of psyllids (Table 1) and the number of ZCpositive tubers collected during this season (Table 3 ).

Lso haplotyping of the positive tubers showed contrasting results for the two outbreak years 2012 and 2016, and an unexpected discrepancy was observed between Lso haplotype prevalence found in psyllid and potato samples. Specifically, all haplotyped tubers were infected with LsoA in 2012 (Table 3). This was fully consistent with the Lso haplotype that could be identified in psyllids collected on sticky cards in Idaho potato fields that same year, in 2012, which was only LsoA (Dahan et al. 2017), and with what was already reported for tubers from 2011 and 2012 in Idaho (Wen et al. 2013). Starting in 2013, LsoB could be found in Lso-positive tubers, and it was the only haplotype detected in potato tubers in the years 2013, 2014, and 2017 (Table 3), whereas psyllids harbored both LsoA and LsoB haplotypes in 2013 through 2015 (Dahan et al. 2017). Starting in 2016 and through the 2018 season, LsoB became the only haplotype of the bacterium found in psyllids caught in southern Idaho (Dahan et al. 2017) (this work). This contrasted with the presence of LsoA found in tuber samples in 2015, 2016, and 2018 (Table 3). In 2015, 2017, and 2018, the availability of tubers for testing was low, and the discrepancy in prevalence of LsoA and LsoB Lso in tubers and psyllids could be explained by these low tuber numbers. However, in 2016, the numbers of Lso-positive psyllids and tubers were higher, and a trend became visible, with LsoB being the only haplotype found in psyllids and an almost equal mixture of LsoA and LsoB found in tubers (Tables 1 and 3).

Clearly, there were at least two separate inoculum sources for the Lso found in potato tubers in 2016, resulting in either LsoA- or LsoBinfected potato plants. Given the strict dependence of the bacterium on psyllids for transmission, several explanations may be discussed. First, it is possible that LsoA psyllids were present in the fields in 2016 but were not caught or were not haplotyped, because a preponderance of positive psyllids could not be haplotyped owing to technical reasons $(\sim 61 \%)$ (Table 3$)$. This explanation assumes that the psyllid monitoring network deployed in southern Idaho (Wenninger et al. 2017) somehow excluded areas inhabited by LsoA-carrying psyllids, especially after 2015 . Second, so far, no correlation was described between the Lso haplotypes present in psyllids and the haplotypes found in the plants and/or tubers. It is generally thought that
ZC-infected plants acquire the disease exclusively through transmission by the vector, but another possibility could be that the LsoAharboring tubers are progeny of infected seed tubers. Although having a significantly reduced sprouting rate and growth, ZCinfected seed tubers could be grown and generate progeny tubers (Henne et al. 2010). Third, another explanation could be that, although the tested tubers were for the most part selected during preparation for storage, they might also come from growing areas outside Idaho, where LsoA may be more abundant than in Idaho. Two tubers carrying both LsoA and LsoB were also found in 2016 (Table 3). Albeit exceptional, this is not unusual and has already been described in Texas samples (Wen et al. 2013). Psyllids also can carry both haplotypes at the same time, but no data are available on the efficiency of transmission of one haplotype over the other, although it has been shown that LsoB reduced nymphal survival rate (Yao et al. 2016).

The data reported here complement our knowledge of psyllid and Lso infestation in the potato fields of Idaho. We could demonstrate that, although Lso was present at a basal level in psyllids during 2013 to 2018, infected tubers could still be found during the same period, indicating a constant disease pressure in the fields that can result in more or less severe outbreaks on occasion as reported for 2012 and 2016. The lack of correlations between Lso haplotypes detected in tubers and psyllids over the same seasons, although surprising, raises concerns about transmission and infectivity of one haplotype over the other and calls for more studies on the vector and the bacterium to better understand the pathogenicity of Lso and epidemiology of the $\mathrm{ZC}$ disease.

\section{Acknowledgments}

We thank Justin Ruhl for providing potato tubers and Alicia Hodnik and César Reyes for help with the sample processing. For assistance with managing the potato psyllid monitoring network, we thank Lucy Standley, Amy Carroll, Lynn Woodell, James Woodhall, Mike Thornton, Oksana Adams, Kasia Duellman, Melissa Bertram, Jill Randall, Melinda Lent, Jennifer Riebe, Tom Salaiz, Drew Glascock, Jeff Miller, Janan Claiborn, Anastasia Stanzak, Cheryn Clayton, Tucker Daley, Wyatt Shewmaker, Austin Fife, and Trent Taysom.

\section{Literature Cited}

Alfaro-Fernández, A., Hernández-Llopis, D., and Font, M. I. 2017. Haplotypes of 'Candidatus Liberibacter solanacearum' identified in umbeliferous crops in Spain. Eur. J. Plant Pathol. 149:127-131.

Bohs, L., and Olmstead, R. G. 2001. A reassessment of Normania and Triguera (Solanaceae). Plant Syst. Evol. 228:33-48.

Crosslin, J. M., Hamm, P. B., Eggers, J. E., Rondon, S. I., Sengoda, V. G., and Munyaneza, J. E. 2012a. First report of zebra chip disease and "Candidatus Liberibacter solanacearum" on potatoes in Oregon and Washington state. Plant Dis. 96:452.

Crosslin, J. M., Lin, H., and Munyaneza, J. E. 2011. Detection of 'Candidatus Liberibacter Solanacearum' in the potato psyllid, Bactericera cockerelli (Sulc), by conventional and real-time PCR. Southwest. Entomol. 36:125-135.

Crosslin, J. M., Olsen, N., and Nolte, P. 2012b. First report of zebra chip disease and "Candidatus Liberibacter solanacearum" on potatoes in Idaho. Plant Dis. 96:453.

Dahan, J., Wenninger, E. J., Thompson, B., Eid, S., Olsen, N., and Karasev, A. V. 2017. Relative abundance of potato psyllid haplotypes in Southern Idaho potato fields during 2012 to 2015, and incidence of 'Candidatus Liberibacter solanacearum' causing zebra chip disease. Plant Dis. 101:822-829.

Dellaporta, S. L., Wood, J., and Hicks, J. B. 1983. A plant DNA minipreparation Version II. Plant Mol. Biol. Report. 1:19-21.

Haapalainen, M. L., Wang, J., Latvala, S., Lehtonen, M. T., Pirhonen, M., and Nissinen, A. I. 2018. Genetic variation of 'Candidatus Liberibacter solanacearum' haplotype C and identification of a novel haplotype from Trioza urticae and stinging nettle. Phytopathology 108:925-934.

Hajri, A., Loiseau, M., Cousseau-Suhard, P., Renaudin, I., and Gentit, P. 2017 Genetic characterization of 'Candidatus Liberibacter solanacearum' haplotypes associated with apiaceous crops in France. Plant Dis. 101: 1383-1390.

Hansen, A. K., Trumble, J. T., Stouthamer, R., and Paine, T. D. 2008. A new Huanglongbing species, "Candidatus Liberibacter psyllaurous," found to infect tomato and potato, is vectored by the psyllid Bactericera cockerelli (Sulc). Appl. Environ. Microbiol. 74:5862-5865.

Harrison, K., Tamborindeguy, C., Scheuring, D. C., Herrera, A. M., Silva, A., Badillo-Vargas, I. E., Miller Jr., J. C., and Levy, J. G. 2019. Differences in zebra chip severity between 'Candidatus Liberibacter Solanacearum' haplotypes in Texas. Am. J. Potato Res. 96:86-93. 
Henne, D. C., Workneh, F., and Rush, C. M. 2010. Movement of Bactericera cockerelli (Heteroptera: Psyllidae) in relation to potato canopy structure, and effects on potato tuber weights. J. Econ. Entomol. 103:1524-1530.

Holeva, M. C., Glynos, P. E., and Karafla, C. D. 2017. First report of 'Candidatus Liberibacter solanacearum' on carrot in Greece. Plant Dis. 101:1819.

Liefting, L. W., Perez-Egusquiza, Z. C., Clover, G. R. G., and Anderson, J. D. 2008. A new 'Candidatus Liberibacter' species in Solanum tuberosum in New Zealand. Plant Dis. 92:1474.

Liefting, L. W., Sutherland, P. W., Ward, L. I., Paice, K. L., Weir, B. S., and Clover, G. R. G. 2009. A New 'Candidatus Liberibacter' species associated with diseases of solanaceous crops. Plant Dis. 93:208-214.

Munyaneza, J. E. 2012. Zebra chip disease of potato: Biology, epidemiology, and management. Am. J. Potato Res. 89:329-350.

Munyaneza, J. E. 2015. Zebra chip disease, Candidatus Liberibacter, and potato psyllid: A global threat to the potato industry. Am. J. Potato Res. 92:230-235.

Munyaneza, J. E., Crosslin, J. M., and Buchman, J. L. 2009a. Seasonal occurrence and abundance of the potato psyllid, Bactericera cockerelli, in South Central Washington. Am. J. Potato Res. 86:513-518.

Munyaneza, J. E., Crosslin, J. M., and Upton, J. E. 2007. Association of Bactericera cockerelli (Homoptera: Psyllidae) with "Zebra Chip," a new potato disease in Southwestern United States and Mexico. J. Econ. Entomol. 100:656-663.

Munyaneza, J. E., Sengoda, V. G., Aguilar, E., Bextine, B. R., and McCue, K. F. 2013. First report of 'Candidatus Liberibacter solanacearum' infecting eggplant in Honduras. Plant Dis. 97:1654.

Munyaneza, J. E., Sengoda, V. G., Aguilar, E., Bextine, B., and McCue, K. F. 2014. First report of 'Candidatus Liberibacter solanacearum' on pepper in Honduras. Plant Dis. 98:154.

Munyaneza, J. E., Sengoda, V. G., Crosslin, J. M., Garzón-Tiznado, J. A., and Cardenas-Valenzuela, O. G. 2009b. First report of "Candidatus Liberibacter solanacearum" in tomato plants in México. Plant Dis. 93:1076.

Mustafa, T., Horton, D. R., Cooper, W. R., Swisher, K. D., Zack, R. S., Pappu, H. R., and Munyaneza, J. E. 2015. Use of electrical penetration graph technology to examine transmission of 'Candidatus Liberibacter solanacearum' to potato by three haplotypes of potato psyllid (Bactericera cockerelli; Hemiptera: Triozidae). PLoS One 10:e0138946.

Nelson, W. R., Fisher, T. W., and Munyaneza, J. E. 2011. Haplotypes of Candidatus Liberibacter solanacearum suggest long-standing separation. Eur. J. Plant Pathol. 130:5-12.

Nelson, W. R., Sengoda, V. G., Alfaro-Fernandez, A. O., Font, M. I., Crosslin, J. M., and Munyaneza, J. E. 2013. A new haplotype of Candidatus Liberibacter solanacearum identified in the Mediterranean region. Eur. J. Plant Pathol. 135:633-639.

Pitman, A. R., Drayton, G. M., Kraberger, S. J., Genet, R. A., and Scott, I. A. W. 2011. Tuber transmission of 'Candidatus Liberibacter solanacearum' and its association with zebra chip on potato in New Zealand. Eur. J. Plant Pathol. 129:389-398.

Rashed, A., Workneh, F., Paetzold, L., Gray, J., and Rush, C. M. 2014. Zebra chip disease development in relation to plant age and time of 'Candidatus Liberibacter solanacearum' infection. Plant Dis. 98:24-31.

Rondon, S. I. 2012. Zebra Chip update in the lower Columbia Basin of Oregon and Washington: First year retrospective toward managing the disease. Pages 70-73 in: Proceedings of the 12th Annual Zebra Chip Reporting Session, San Antonio, TX. F. Workneh, A. Rashed, and C. M. Rush, eds.

Secor, G. A., Rivera, V. V., Abad, J. A., Lee, I.-M., Clover, G. R. G., Liefting, L. W., et al. 2009. Association of 'Candidatus Liberibacter solanacearum' with zebra chip disease of potato established by graft and psyllid transmission, electron microscopy, and PCR. Plant Dis. 93:574-583.

Secor, G. A., and Rivera-Varas, V. 2004. Emerging diseases of cultivated potato and their impact on Latin America. Rev. Latinoam. Papa Suppl. 1:1-8.

Swisher, K. D., Henne, D. C., and Crosslin, J. M. 2014. Identification of a fourth haplotype of Bactericera cockerelli (Hemiptera: Triozidae) in the United States. J. Insect Sci. 14:161.
Swisher, K. D., Munyaneza, J. E., and Crosslin, J. M. 2012. High resolution melting analysis of the Cytochrome Oxidase I gene identifies three haplotypes of the potato psyllid in the United States. Environ. Entomol. 41:1019-1028.

Swisher, K. D., Munyaneza, J. E., and Crosslin, J. M. 2013a. Temporal and spatial analysis of potato psyllid haplotypes in the United States. Environ. Entomol. 42 381-393.

Swisher, K. D., Sengoda, V. G., Dixon, J., Echegaray, E., Murphy, A. F., Rondon, S. I., Munyaneza, J. E., and Crosslin, J. M. 2013b. Haplotypes of the potato psyllid, Bactericera cockerelli on the wild host plant, Solanum dulcamara, in the Pacific Northwestern United States. Am. J. Potato Res. 90:570-577.

Swisher Grimm, K. D., and Garczynski, S. F. 2018. Identification of a new haplotype of 'Candidatus Liberibacter solanacearum' in Solanum tuberosum. Plant Dis. 103:468-474.

Swisher Grimm, K. D., Mustafa, T., Rodney Cooper, W., and Munyaneza, J. E. 2018. Role of 'Candidatus Liberibacter solanacearum' and Bactericera cockerelli haplotypes in zebra chip incidence and symptom severity. Am. J. Potato Res. 95:709-719.

Tahzima, R., Massart, S., Achbani, E. H., Munyaneza, J. E., and Ouvrard, D. 2017 First report of 'Candidatus Liberibacter solanacearum' associated with the psyllid Bactericera trigonica Hodkinson on carrots in Northern Africa. Plant Dis. 101:242.

Teresani, G. R., Bertolini, E., Alfaro-Fernández, A., Martínez, C., Tanaka, F. A O., Kitajima, E. W.,Roselló, M., Sanjuán, S., Ferrándiz, J. C., López, M. M., Cambra, M., and Font, M. I. 2014. Association of 'Candidatus Liberibacter solanacearum' with a vegetative disorder of celery in Spain and development of a real-time PCR method for its detection. Phytopathology 104:804-811.

Thinakaran, J., Horton, D. R., Cooper, W. R., Jensen, A. S., Wohleb, C. H., Dahan, J., Mustafa, T., Karasev, A.V., and Munyaneza, J. E. 2017. Association of potato psyllid (Bactericera cockerelli; Hemiptera: Triozidae) with Lycium spp. (Solanaceae) in potato growing regions of Washington, Idaho, and Oregon. Am. J. Potato Res. 94:490-499.

U.S. Department of Agriculture-Economic Research Service. 2016. Vegetables and Pulses. USDA-ERS, Beltsville, MD.

Wen, A., Johnson, C., and Gudmestad, N. C. 2013. Development of a PCR assay for the rapid detection and differentiation of 'Candidatus Liberibacter solanacearum' haplotypes and their spatiotemporal distribution in the United States. Am. J. Potato Res. 90:229-236.

Wen, A., Mallik, I., Alvarado, V. Y., Pasche, J. S., Wang, X., Li, W., Levy, L., Lin, H., Scholthof, H. B., Mirkov, T. E., Rush, C. M., and Gudmestad, N. C. 2009. Detection, distribution, and genetic variability of 'Candidatus Liberibacter' species associated with zebra complex disease of potato in North America. Plant Dis. 93:1102-1115.

Wenninger, E. J., Carroll, A., Dahan, J., Karasev, A. V., Thornton, M., Miller, J., Nolte, P., Olsen, N., and Price, W. 2017. Phenology of the potato psyllid, Bactericera cockerelli (Hemiptera: Triozidae), and "Candidatus Liberibacter solanacearum" in commercial potato fields in Idaho. Environ. Entomol. 46: 1179-1188.

Wenninger, E. J., Dahan, J., Thornton, M., and Karasev, A. V. 2019. Associations of the potato psyllid and "Candidatus Liberibacter solanacearum" in Idaho with the non-crop host plants bittersweet nightshade and field bindweed. Environ. Entomol. 48:747-754.

Wenninger, E. J., Olsen, N., Thornton, M., Nolte, P., Miller, J., Dahan, J., et al 2014. Three years of monitoring potato psyllids, "Candidatus Liberibacter solanacearum," and zebra chip in Idaho. Pages 6-8 in: Proceedings of the 14th Annual SCRI Zebra Chip Reporting Session, Portland, OR. F. Workneh and C. M. Rush, eds.

Yao, J., Saenkham, P., Levy, J., Ibanez, F., Noroy, C., Mendoza, A., Huot, O., Meyer, D. F., and Tamborindeguy, C. 2016. Interactions "Candidatus Liberibacter solanacearum"-Bactericera cockerelli: Haplotype effect on vector fitness and gene expression analyses. Front. Cell. Infect. Microbiol. 6:62. 